\title{
The habitus of digital scholars
}

\author{
Cristina Costa* \\ Centre for Lifelong Learning, School of Education, University of Strathclyde, Glasgow, UK \\ (Received 30 April 2013; final version received 1 October 2013)
}

\begin{abstract}
This article concerns the Participatory Web and the impact it has on academic researchers' perceptions of digital scholarship practices. The Participatory Web, as a space of active involvement, presence and socialisation of knowledge, has the potential to introduce significant changes to scholarly practice and to diversify it. This article draws on the findings of a narrative inquiry study that investigated the habitus of 10 digital scholars. The study uses Bourdieu's concepts of habitus, field, and social and cultural capital as a research lens. One of the main findings to come out of the study was that research participants' approaches to digital scholarship practices are highly influenced by their online social capital, the online networks that influence their thinking and outlook on scholarly practices, including their advocacy of openness and transparency of academic practice. This article concludes by highlighting the dispositions digital scholars display in an attempt to characterise the values and beliefs that underpin their scholarly practices.
\end{abstract}

Keywords: digital scholarship; habitus; social capital; cultural capital; the Participatory Web; Pierre Bourdieu

\section{Introduction}

This article reports on the perceptions of scholars regarding the effects of the Participatory Web on their research practices. It uses Bourdieu's concepts of habitus, field, and social and cultural forms of capital to examine emerging approaches to scholarly activity in the current digital economy. Habitus can be broadly defined as the evolving process through which individuals act, think, perceive and approach the world, and their role in it. Habitus is thus influenced by the social, cultural and economic circumstances to which the individual is exposed.

In the context of this research, the Participatory Web is understood as a set of digital communicating networks, applications and environments on which individuals act as active participants, contributors, and co-creators of information, knowledge and opinions. The term digital scholarship practice is used in this article to mean the activities scholars conduct in connection with the Participatory Web. In this sense, digital scholarship practices are seen as scholarly activities supported and enhanced by the Participatory Web and the ideas and behaviours associated with it. Digital scholarship practices are strongly rooted in a culture of sharing, openness and transparency.

*Corresponding author. Email: cristina.costa@strath.ac.uk 


\section{Costa}

Using a narrative inquiry methodology enabled the researcher to study the interplay between the individual's ever-forming social and cultural forms of capital. This allowed the researcher to elaborate on the habitus of digital scholars and draw conclusions on the dispositions they acquire through their active involvement in the Participatory Web and in the knowledge networks that co-exist therein. Research participants' approach to using the Participatory Web goes beyond the mere access and publishing of academic knowledge; it also, and above all, comprises their involvement and participation in knowledge networks that actively advocate the openness of scholarly work, that is, more radical forms of changing scholarship than those that are typically associated with academia. The dispositions and attitudes scholars develop through their involvement in knowledge networks that are mediated by the Participatory Web make their approach to scholarship practice a distinct one. These dispositions will be illustrated in later sections of the article.

\section{The Participatory Web in academia}

The Participatory Web is often categorised by the emergence of social network sites, multi-channel communication tools, different types of content (Krishnamurthy and Cormode 2008), and a diverse and wide range of users spread across the globe who use the web as a space of congregation and participation. As such we have witnessed a reciprocal effect between technology and human behaviour, in that individuals can shape technology and technology can also shape the individual's approach through the affordances it provides (McLuhan 1964). Although the Participatory Web is a fairly recent phenomenon, it is having a fast, growing influence in the current knowledge economy (Powell and Snellman 2004). New approaches to how knowledge is constructed and communicated are starting to emerge as alternatives to the practices typically associated with academia. These emergent approaches include open and distributed forms of participation, crowdsourcing, open-access publications and other genres of communication and networking such as blogging and microblogging.

The current technological infrastructure, with its participatory features, gives the user autonomy to create and publish information, and co-participate in the construction of shared knowledge. Thus, the control of knowledge production and its dissemination is starting to shift from the institution to the individual (Eijkman 2010) and from official to more informal sources and platforms. This not only comes to question the long-established structures within which higher education operates (Hessels and van Lente 2008), but it also stimulates new approaches to the creation, dissemination, use and repurposing of information. It should be remembered however, that while the Participatory Web has become an almost ubiquitous technology, especially in developed countries (Lenhart et al. 2010), online participation is unevenly distributed in the global community. Thus it is far from being an ideal, equal democratic or accessible environment (Naughton 2012). The Participatory Web is also governed by control policies (Deibert 2009; Liang and Lu 2010). Power relations and politics do exist online. They are transferred from face-to-face practices into the online environments (Cammaerts 2008). Nonetheless, the Participatory Web has also proven to be a conduit for self and collective expression (Levy 1997; Surowiecki 2005), social activism (Hjorth and Arnold 2011; Jones 2011; Ray 2011; Shirky 2011), civic engagement and citizenship (Bennett, Wells, and Freelon 2011; Rheingold 2007; Zimmer 2008). 
The creative work of individuals who are active online is the primary source of content on the Participatory Web (Kylie 2008). As the possibilities for the development of collective intelligence and engagement change, so does the practice of those who have an active role online. This has the potential of providing academics with a wide range of opportunities and of making their work more accessible to a larger and more diverse audience. Consequently, it may start to reshape the conventions and traditions associated with the production and communication of knowledge in academia. In this vein, this article looks at the perceptions of academic researchers engaged in digital scholarship practices and how they understand their scholarly practices to have changed as a result of their participation on the Web. The next section will contextualise the Participatory Web within the current changes that affect knowledge creation and introduce the researcher's understanding of digital scholarship practices.

\section{Contextualising the Participatory Web as a catalyst for change}

The current technological changes that affect society impact on the way individuals engaged in knowledge work conduct their activities, the new goals they are required to achieve, and the tools they use to perform their jobs. The Internet and the Web have changed individuals' social and personal spaces of interaction and activity. And it has influenced the workplace in general as a consequence (Nobel and Lupton 1998; Townsend, DeMarie, and Hendrickson 1998). It is argued that it is also influencing academia in specific ways (Conole 2012; Weller 2011), such as in the creation of new forms of communication of scholarly work. Its influence is not only stressed in the technological affordances and opportunities it provides (Anderson and Dron 2011, 2012) but also in the new working cultures and approaches it inspires. The Open Access Movement, for example, questions the ownership and accessibility of knowledge produced in academia. It also advocates the transparency of the processes of knowledge production. In doing so, it challenges established conventions with proposals for new practices. Nonetheless, the adoption of technology in the work place has not only been marked by new ideas and innovation; it has also been used to serve the purpose of managerialist strategies by mediating the standardisation and commercialisation of goods (Attwell 2006), as well as the automation of the workplace. As such, it has failed to truly stimulate new practices in the workplace that would be congruent with individuals' activities in a wider digital context.

Nonetheless, the social and participatory features of the Web are starting to affect the world of knowledge and knowing (Bonk 2009; Brown 2002; Choo et al. 2000; Levy 2009). By giving individuals a more autonomous role where their creative input can be materialised in online environments, individuals may take the initiative to learn with each other, network and generate new content outside any formal working and/or educational structures. Yet, it is also true that the current Web infrastructure is also being used to restrict and limit knowledge. Such is the case of publishing houses that produce some of the most prominent academic publications and use the Web to give paid access to academic work. Hence, it can be argued that although the Participatory Web is changing practices, its effect is not always positive (Naughton 2012). It is not the first-time technology has made a difference in how information is used and managed, or impacts on society both positively and negatively. In doing so, its purpose and value are questioned and challenged (Drucker 1998). Such is the case of emerging digital scholarship practices. 


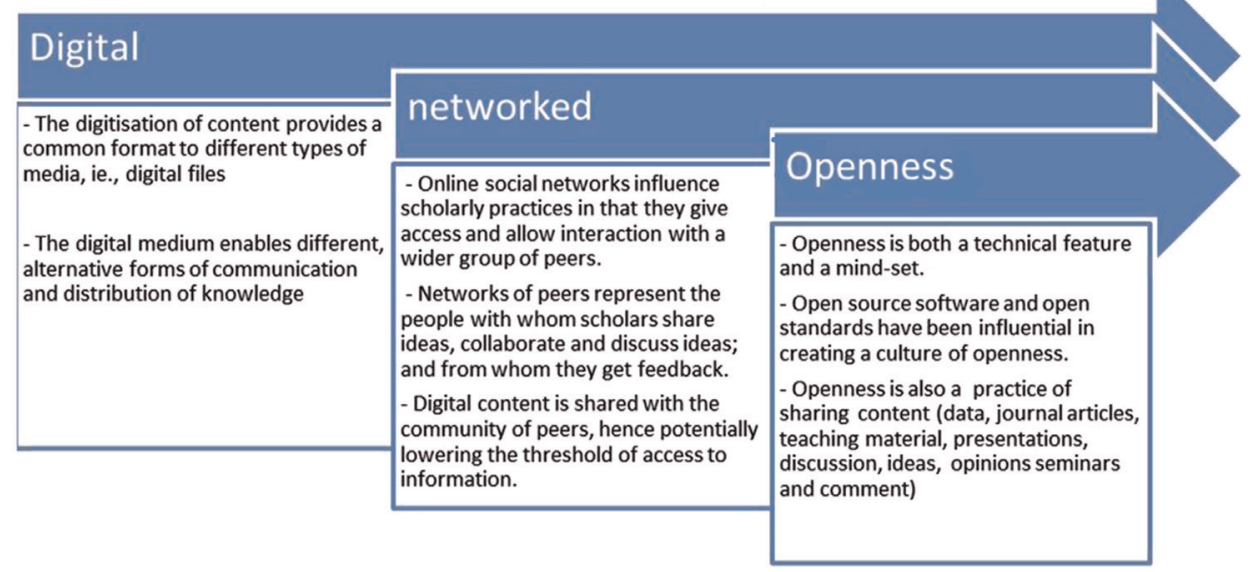

Figure 1. Digital scholarship practices. Compiled and adapted from Weller (2011), Chapter 1, pages $5-9$.

Scholarship practices supported by the Participatory Web can be, according to Weller (2011), synonymous with 'digital, networked and open' (p. 5) practices, as illustrated in Figure 1.

Figure 1 presents the three main features of digital scholarship practices. Digital technologies - the Web - have become a conduit for supporting scholarly practices. It enables the digitisation of content and alternative forms of communication and distribution of knowledge. The possibility of forming and participating in extended networks of peers may influence scholars' practices as they are exposed to a wide range of ideas and approaches. Scholars' online networks are a driving force behind the approach to scholarly practices supported by digital media. Although 'digital' and 'networked' are key features in Weller's approach to digital scholarship, the main feature transforming academic practices - though dependent on the other two presented above - is openness:

Digital content, distributed via a global network, has laid the foundation for potential changes in academia, but it is when the third element of openness is added in that more fundamental challenges to existing practice are seen. (Weller 2011, p. 8)

Openness is a distinct innovation in digital scholarship; the most distinct form of using the Participatory Web to make scholarly work and the processes associated with it available to a wider audience. In short, the Participatory Web facilitates alternative forms of scholarship (Veletsianos and Kimmons 2012) through the sociotechnological infrastructure it provides and from which knowledge networks form and evolve to materialise new approaches to practice, such as emerging cultures of sharing and openness. Digital Scholarship is a growing example of such a phenomenon. At the same time, the new technological developments can also be used to restrict access and control who has access to information and what is published. This article acknowledges the different ways in which the Participatory Web may affect knowledge work, particularly research as a component of academic practice (Boyer 1990). Nonetheless, this article will focus on the accounts of academic researchers who have experienced the Participatory Web in the context of their research activity and perceive it as an important catalyst for change in their own practice. 
In doing so, this research presents the dispositions that inform the habitus of scholars who embrace the key features of digital scholarship practices, namely those related to 'digital, networked and open' scholarly activities. These Key elements of digital scholarship inspire cultures of participation, sharing, openness and transparency amongst scholars who perceive the Participatory Web as a tool and a conduit to transform the academic knowledge industry, and subsequently their own scholarship practices.

\section{The study: narratives of change}

This study explores the perceptions of 10 academic researchers regarding their active involvement in digital scholarship practices. Research, as an element of scholarship practice (Boyer 1990), became the focus of the study. Thus, research participants were recruited following a purposive sampling technique, as it lends itself to 'selecting information-rich cases for study in depth' (Patton 1990, p. 169). This technique allowed me to work with research participants who exhibited given characteristics that make them a representative group (Topp, Barker, and Degenhardt 2004) of academic researchers engaged in digital scholarship practices.

The selection criteria designated for this study meant that research participants:

(1) were active researchers in an academic setting, that is, were employed as academics in higher education institutions.

(2) were active and prolific users of the Participatory Web as part of their professional activity.

(3) had a web presence online, that is, their digital footprint was accessible and interactive.

The study used a narrative inquiry methodology and followed an iterative process to collect and analyse narratives of online practice of research participants. The interviews - centred on the topics of networking, inter-communication and dissemination of research - followed a spontaneous pattern of conversation as a form of providing the research participants with ownership of their stories of practice without losing sight of the interview guide. This allowed the researcher to elicit research participants' own experiences and perspectives through their own words and accounts (Bruner 1991; Clandinin 2006; Clandinin and Connelly 2004; Riessman 1993), and consequently identify relevant research themes connected to digital scholarship practices.

Additional methods of data collection were also employed to create a richer research narrative. These included field notes that served to remember and record research participants' reactions to what they were narrating, and comments generated from the interactions between the researcher and research participants as part of giving research participants access to my first interpretation of their narratives of practices.

The research data were coded thematically and analysed narratively to access the social meanings behind research participants' narratives (Bruner 1992; Lawler 2002; Patton 2002), that is, narrated interpretations of lived experiences and events enclosed in a social, cultural, historical, economic and political space. Bourdieu's key concepts (social and cultural forms of capital, habitus and field) were used to code the data. Research participants' statements were analysed and considered in light of the current social milieu with Bourdieu's key concepts providing an incisive interpretation of the research narratives. 


\section{Costa}

\section{Bourdieu's concepts}

\section{Habitus}

Bourdieu's work enables a critical interpretation of social phenomena, particularly related with the (re)production and changes of social practices. His key concepts present a framework to understand social action (Elam 2008). Thus, some of Bourdieu's key concepts were used to analyse research participants' perceptions of their digital practices, namely, research as an element of scholarship.

For Bourdieu, habitus consists of internalised behaviours and perceptions that each individual has implicitly acquired and will continue to 'accumulate' throughout their existence. In this sense, 'the habitus, a product of history, produces individual and collective practices - more history' (Bourdieu 1990b, p. 54). Habitus is partly connected to individuals' experiences and the rituals, norms and approaches to which they are exposed or in which individuals are involved. Habitus is equally related to the social and professional environments in which they participate and that inevitably influence and are reflected in their practice, given that 'socialised agents ... are endowed with transindividual dispositions' (Bourdieu 1990a, p. 150).

Habitus can also be broadly defined as the evolving process through which individuals act, think, perceive and approach the world and their role in it. As such, habitus does not exist on its own. It connects the individual to the social environments in which he/she exists and performs, that is, the field, and where his/her practice is materialised and thus justified.

Habitus can thus be seen as an agent of continuity and tradition. Yet, depending on the context and on the individual's dispositions, it can also be an agent of innovation and transformation of practice. Bourdieu states that 'as an acquired system of generative schemes, the habitus makes possible the free production of all the thoughts, perceptions and actions inherent in the particular conditions of its productions' (1990a, p. 55), thus providing scope for alteration and evolution of practice. In this vein, this article focuses on the habitus of academics who embrace digital forms of scholarship as defined by Weller (2011 - see Figure 1), and who are therefore herein referred to as digital scholars. This article looks at the dispositions of the research participants, which make up their habitus, in relation to the field of the Participatory Web and how it influences their current approach to academic practice, namely research.

Reay (2004) points out that 'dispositions are inevitably reflective of the social context in which they [are] acquired' (p. 435) and tend therefore to be reproduced in those social spaces without necessarily having a transformative effect beyond them (Bourdieu 1990a, p. 64).

An individual's habitus is also interlinked with the forms of capital that characterise him/her.

\section{Forms of capital}

Bourdieu $(1985,1986)$ talks about four types of capital:

- Social capital (change and increase of network links and social bonds; interrelationship amongst individuals)

- Cultural capital exists in an embodied state (dispositions, principles and values); an objectified state (physical, cultural assets individuals acquire also 
within their family and social circles); and also in an institutionalised state (institutionalised recognition, often typified by educational qualifications)

- Economic capital (epitomised mainly by financial wealth)

- Symbolic capital (a form of prestige, reputation and distinction that is automatically translated into economic capital).

Social capital is visible in the relationships established between individuals. The heart of individuals' social capital is in their spheres of influence, that is, the networks individuals are able to foster and the level of trust they are able to cultivate, through the interrelationships they develop within those social groups. Communication is a vital currency of social capital; the glue of social interrelationships between social actors. These social bonds can be seen as having a transformative effect on individuals' practices (Bourdieu 1985) given that individuals, as social agents, often assimilate the viewpoints and conventions associated with the groups to which they belong.

Social capital can also have an increasing effect on one's cultural capital, especially in its embodied form. The on-going acquisition of embodied cultural capital is party rooted in an individual's family background and the communities he/she joins and participates in during his/her trajectory. It is also derived from the interactions an individual establishes with given groups or networks, how he/she identifies him/herself with it, and progressively adopts their ways of thinking which are then manifested through an individual's dispositions towards the realities and practices they have to tackle. An individual's cultural capital justifies their social standing (Grenfell 2008). Embodied cultural capital becomes visible by the way it imposes itself on the habitus of the individual.

In this article, I will focus mainly on social capital and (embodied) cultural capital and how it shapes individuals' academic habitus. Yet, it is inevitably not to note how they impact or are impacted by economic and symbolic forms of capital. The different forms of capital and the individual's habitus are always in flow with the field, that is, the social space in which individuals operate.

\section{Field}

Crucial to Bourdieu's work is also the concept of field. Field is the social space(s) in which individuals co-exist, act and interact, and which in return influences the individual's practice.

A social field provides its agents with roles that define their positions and actions within a given social context. And, as a consequence, it also becomes a space in which individuals acquire and display their different forms of capital. The field as a social space can also be a space of tensions and struggles as its rules might not always be aligned with an individual's ideas and purposes. The opposite can also be true.

Individuals can belong to different social fields with each presenting its own rules and conventions. Bourdieu points out that:

the process of differentiation of the social world which leads to the existence of autonomous fields concerns both being and knowledge. [Moreover] in differentiating itself, the social world produces differentiation of the modes of knowledge of the world. To each of the fields there corresponds a fundamental point of view on the world which creates its own objects and finds in itself the principle of understanding and explanation appropriate to that object. (2000, p. 99)

It is also important to note that there is a visible complicity between an individual's habitus and the social fields in which they interact. Both field and habitus are 


\section{Costa}

mutually dependent given that they are constantly influencing one another, even if they do so unconsciously (Bourdieu 2000, pp. 150-151).

This research looks at the Participatory Web as a field of interaction; the social context that influences and justifies the habitus of scholars involved in digital practices. In this sense, the habitus of the research participants will be considered in relation to the social context in which it is inserted.

\section{Digital scholars' narratives of practice}

This research has studied the perceptions of academic researchers regarding their use of the Participatory Web as part of their scholarly activity, especially research. In doing so, this article has found that, in general, research participants shared the strong perception that their use of the Participatory Web has influenced their approaches to practice. This is particularly evident in the way research participants report about exploring the affordances of digital technologies for their scholarly practice. The new forms of networking and participating online allow them to exchange and co-create ideas, take part in distributed networks and communities of interest, and even engage in different forms of sociability in which online and face-toface practices become often interwoven. Their approaches to open practices, such as their support for the Open Access Movement, also seem to be the most distinct factor that characterises their digital scholarly activity.

Moreover, research participants' approach to digital forms of scholarship seems to be motivated by the desire to reinvigorate their own practice with new ideas and approaches, as they are exposed to them and encouraged to do so through the networks to which they belong. As a result of their active participation online, research participants congregate with other knowledge workers who have similar views regarding how scholarship in the digital age should be carried out. These networks become both sources of new knowledge and of support given that they influence and encourage the openness of scholarly practices with digital tools and the processes associated with working and socialising online.

\section{The Participatory Web: a field of change}

The integration of the Participatory Web in scholarly practice means a change in the conventions of (co-)creating, discussing and making new knowledge more accessible to different audiences. Research participants featured in this research reported their perceptions of the Participatory Web and how it has influenced and/or stimulated changes in their approach to scholarly work. Research participants' perceptions will be described in connection with Weller's (2011) characteristics of digital scholarship: (1) Digital, (2) Networked and (3) Open, as illustrated in Figure 1, before employing a Bourdieuian research lens for the analysis of the data. Weller's categorisation will serve as a framework to tease out research participants' habitus with regard to their scholarship practices with the influence of the Participatory Web.

\section{Digital}

According to Weller (2011), one of the aspects of digital scholarship is the fact that scholarship can now be digital, that is, knowledge can be digitised and digital technologies offer alternatives to the dissemination of knowledge through the new 
channels they make available. This gives a new dimension to conventional forms of scholarship and may question established approaches to practice. The research participants see practicing scholarship with the support of the Participatory Web as a form of breaking away from the classic canons of knowledge work. It is also perceived as a form of innovating practice:

For the classic professor the valuable things are face-to-face ... but there is a new way to collaborate, to introduce your research and this is definitely online. (RP10)

The fact that the research participants are increasingly relying on digital forms of finding and producing knowledge not only sets them apart from those who have not yet embraced digital forms of scholarship; their digital approaches to conducting their scholarly practice also give them a distinct sense of identity.

In this sense, the Participatory Web is seen as a 'defining difference between colleagues and the [research participant(s)]' (RP9); one that also makes the research participants 'stand out from the rest of the researchers' (RP4). The research participants' use of the Participatory Web to support and enhance their research practices reveals their convictions regarding scholarship and draws a distinction between their approaches and the approaches of those who rely on more conventional practices. The digital space of participation in which their scholarly activity takes place creates that differentiation.

Nonetheless, the reasons behind the adoption of digital practices seem to relate to higher stakes than that of prominence and differentiation. Although distinction becomes a side effect of using the Participatory Web in research practice, research participants' interest in the adoption of digital scholarship relates to the fulfilment of their professional goals and values: of networking, sharing knowledge and making their work accessible to a wider audience and different publics:

[it's] about being able to share information. (RP3)

It's opening [research] up to more people, and widening the networks of people that

I know in the field. (RP5)

This leads to the remaining two characteristics of digital scholarship: 'networked' and 'open'.

\section{Networked}

Digital scholarship practices are also characterised by their networking potential. In the words of Weller (2011), this is a key feature for transformative practice (p. 6). It benefits the communities that support and enhance individuals' practices by extending the distribution and discussion of knowledge and new information to collective spaces.

Referring back to the research narratives, networking (establishing dialogues, participating in projects and collaborating with like-minded people via the Web) was a set of practices strongly highlighted in the research narratives:

... that extended network and being able to share has been the big change in research for me. (RP6)

Research participants seem to value the connections they make online and how the links with other individuals have changed and enriched their research practice. 


\section{Costa}

For the research participants, the real value of digital scholarship is in being connected to extended networks, sharing information and practices, and learning from each other. The value research participants place on distributed networks, an affordance of the Participatory Web that individuals exploit to socialise with peers at a global scale, is evident given that it can generate new scholarly activity with individuals who share a similar approach to scholarship:

It's changed for me in terms of collaboration. Technology just makes things so easy now. I've got a global network of people who are interested in working broader. (RP4)

and who also portray similar values and shared purposes:

We're [digital scholars] a group of people who think about these kind of things [digital scholarship practices] seriously, so we can make a difference. (RP10)

The quotes above reveal the importance the Participatory Web has for research participants' practice, first in terms of the influence these social networks have on their research practice given that 'networks of peers are important in scholarship they represent the people who scholars share ideas with, collaborate with on projects, review papers for, discuss ideas with and get feedback from' (Weller 2011, p. 7). Second, it provides opportunities to congregate with people who share similar approaches and principles thus generating value to both the individual and the networks. Research participants' narratives hinted very strongly at the idea of adopting digital scholarship practices as a form of connecting to extended networks and making a difference in their professional practice and personal growth.

In this sense, research narratives also unveiled that participation on the Web cultivates the emergence of non-established practices. Given that digital scholarship practices are still not mainstream practices, it becomes even more important for research participants to participate in social networks that endorse the principles and values with which they associate their approaches to research practice. In those networks, they find a support system that encourages research participants to rethink their scholarly activity:

It has exposed me to totally new ways of thinking, to a culture that is very, very different from the dominant culture in academia. (RP1)

Being able to talk to people and see what other people are doing and engage with other people ... that is probably the biggest impact this way [of working] has had on me. Not just on my research, but on my thinking in general. (RP9)

Without them [online networks] I would be a completely different researcher (...) This kind of contact with people who can enrich your work, your research and your life. (RP10)

The peer networks with which participants engage online have a direct influence on the way they think about their scholarly activity and how they put their ideas into practice. According to the quotes mentioned above the influence exercised by their online networks on their scholarly practice not only contrasts with the dominant practices of their workplace; it also makes research participants feel that their experience as academics is enriched by changing the way they think of their practice. 


\section{Open}

Digital scholarship practice's most challenging component is openness. Openness, in the context of digital scholarship practices, not only refers to the technology but also, and above all, to the 'assumption, desire and ability to share' (Weller 2011, p. 100) content (data, articles, presentations, journals, etc.), ideas and feedback. This is probably the most radical consequence of the digital networking practices from which scholarly activities can benefit.

The research narratives often referred to the notion of the 'openness' of research practice. Research participants framed openness mainly within the context of openaccess journals and other alternative forms of publishing and licensing their work. Research participants' narratives indicated that they advocated and supported the Open Access Movement, because it matched their approach to research practice, as the following statements indicate:

So I think, what on earth is the point of doing research if you cannot contribute to the profession [by offering it to practitioners] (...) I'd rather write a blogpost. (...) so it's very important for me to be transparent. (RP2)

I'm very big on openness and transparency. I put early drafts of papers on public google docs and invite a whole bunch of people to comment (...) If I am going to do something I want as many people as possible to read it. (RP9)

This approach to 'openness' as a form of impact is often mentioned in the research narratives. Research participants' motivation to 'reinvent' their scholarship practice with the Participatory Web can be attributed to their desire to fulfil their professional principles and beliefs. Digital technologies provide them with a structure not only to conduct their practice differently but also to put into practice the ideas that they think will improve and extend their professional contribution. The networks to which research participants belong become support structures that allow them to pursue their approach to digital scholarship practices given their shared purpose. Research participants stressed their support for open practices, which is closely related to their professional values. Alongside openness, transparency was also an issue often raised. Research participants see digital technologies and the affordances they provide as a means to make scholarly practice a transparent process to which other people can have access. This becomes a distinct feature of digital scholarship when compared with the more traditional scholarly practices that do not benefit from the different communication channels the Participatory Web provides for the innovation of knowledge work. In mentioning openness and transparency of academic practices, research participants are evoking their professional values that distinguish them from their immediate colleagues, given that they don't 'feel like the people in [their] department' (RP9). Hence, being a digital scholar not only means using digital technologies but also to be linked to extended networks that influence and shape thinking and practices. Openness and transparency are the principles that they feel most strongly differentiate their approaches to scholarship practices from their institutional peers.

By using Weller's categorisation of digital scholarship, as presented in Figure 1, I was able to sketch a picture of research participants' perceptions of their digital scholarship practices. The adoption of the Participatory Web by digital scholars represents a change in how scholarship can be conducted. Research participants see it as offering alternatives to established scholarly traditions. The adoption of the 


\section{Costa}

Web as a space of participation may also encourage new patterns of working and alternative forms of scholarship.

The research participants featured in this narrative inquiry study are engaged in digital, networked and open scholarly activities. According to their perceptions, their digital scholarship practices, and the values, ideologies and activities associated with it, make their approaches to scholarly work a distinct practice. They see it as setting them apart from other scholars who might be using the Web to assist with their research but who do not necessarily advocate the main principles of digital scholarship practices such as networked learning or the openness of academic work. Having said that, this article does not mean to claim that scholars less engaged in online practices are not familiar with the Participatory Web or that they not use it for scholarly work. On the contrary, it rather aims to denote that scholars pro-actively involved in digital scholarship practices, as defined by Weller (see Figure 1), display a different set of principles and dispositions that makes their scholarly practice a distinct one. This is visible through the research participants' approaches to scholarly work and the scholarship practices that emerge from the online social spaces in which they interact, and which consequently reflect their values and beliefs regarding their academic practice. This aspect will be further discussed in the final section of this article.

In the next section, I will analyse the above mentioned digital scholarship practices, through a Bourdieuian lens to understand what it means in terms of habitus.

\section{The habitus of digital scholars}

The concept of habitus as a system of dispositions with a past, present and also a future is informed by the strategies individuals use when carrying out practices that are in constant development within the conditions of their existence (Bourdieu 2000). Habitus justifies and produces social actions (Bourdieu 1990a) in a given social context and time.

The academic researchers interviewed for this research project reported on the role of the Participatory Web in informing their scholarly practice. Such distinct approaches to practice reflect research participants' habitus. Their dispositions lean towards contemporary forms of knowledge working that aim to make their research practice more open and accessible, transparent, interactive and digital. The interviewed digital scholars revealed a propensity for innovative practice that is translated into their use of the Participatory Web, justified by their intellectual journeys (their embodied capital), and supported by the networks with which they congregate online, that is, a meaningful part of their social capital. One of the research participants alluded to this with the following quote:

I've got an attitude that is quite different from any of my immediate colleagues - let's put it that way - so having ... a network ... [of] people who don't feel so different from me is an extremely important means of external validation .... in addition obviously to the intellectual input that you get. (RP6)

The networks of like-minded people that the research participants find online gives them a sense of reassurance regarding their digital scholarly practices and thus endorse their attitudes towards the Participatory Web; this is one of the reasons why the online networks in which participants are involved are so important to them. 
It also helps define their identity as (digital) scholars. Their networks become a kind of support group which approves of, contributes to and motivates research participants' digital practices. As Bourdieu remind us:

The experience of the world that is taken for granted presupposes the agreement between the dispositions of the agents and the expectations or demands in a world in which they are inserted. (2000, p. 147)

The online environments, and the online knowledge networks, in which participants interact are reportedly characterised by an epistemology of practice that is congruent with their own ideas of how scholarly activity should be conducted. In finding this apparent harmony between their habitus and the field in which their digital activities take place, their approaches to digital scholarship can be fully sustained and developed.

The engagement of participants in online environments has a changing effect on how they approach practice given their convergence with networks of scholars who share similar approaches to scholarship, that is, online social capital. This, per se, makes the Participatory Web a very attractive environment to the participants of this study. It enables them to develop collaborative links and identify synergies that support their approaches towards digital practices. These networks foster and support novel forms of working that institutions may not yet be ready to acknowledge, or in which their immediate academic networks, those in their institution, might not be interested. By participating in distributed networks that share a similar value system regarding the purpose of scholarship, research participants see their approaches validated and are therefore empowered to act in accordance with what they believe scholarship in the 21 st century should be.

Moreover, social capital as 'collectively-owned capital' (Bourdieu 1986, p. 51), in that it contributes to the identity of a group or individual, has the ability of strengthening research participants' dispositions towards scholarly practices. The Participatory Web, the social space in which digital scholarship occurs, is presented as a field that is highly congruent with their dispositions, enabling them to enact and thus strengthen their habitus.

The development of social bonds, mutual support and partnerships via the Participatory Web is often converted not only into shared practice but also into shared embodied cultural capital, as the quote below illustrates well:

I was going to make a creative commons license on all my work ... so I've made that decision. And I made a decision a couple of months ago that whatever publications I do ... that I follow T. A.'s lead and only publish in open access journals, and that has a huge implication for me, because there aren't many credible open access journals in [my area]. (RP2)

The influence of participants' social capital on the values and principles they adopt and advocate (cultural capital) assist us in understanding how research participants' habitus form and evolve with the support of their online networks. Research participants' reported the influence their networks have on their approach to practice and how that transforms their perceptions regarding their own approaches and attitudes towards their own practice:

Technology has very much had an impact on setting me apart from any of my colleagues, but I think even more than that it is how I think about research ... and teaching as a result of using technology (...) when you expose yourself to the wider community you 


\section{Costa}

learn a lot about yourself and what other people are doing (...) I'm now very big on openness and transparency. (RP9)

The research participants' online social and cultural capital play an important role in shaping their views of digital scholarship practices, not only by engaging in shared practices but also by featuring similar beliefs such as those of networking online, encouraging them to advocate openness and transparency in scholarly practices.

Research participants have reported about their support for the openness and transparency of scholarly practice. It matches their conception of what scholarship practices in the digital age should be about. Such practices seem to get the support of their online social capital within the context of the online social spaces in which they interact. Yet, given that individuals belong to and participate in different social spaces, it would be important to understand if the habitus of the research participants, which seem to be in harmony with the field of the Participatory Web, is also in accordance with the other fields on which their practice also impacts, for instance, their academic institutions. Further discussion on this topic will be addressed in another publication.

\section{Conclusions}

This research made use of Weller's (2011) categorisation of digital scholarship practices to interrogate participants' accounts of their scholarly practice to account for their habitus, and in particular, the professional values they associate with digital scholarship. The research pointed out that the habitus of digital scholars is strongly influenced by their online social capital which in return also justifies their embodied cultural capital. The habitus is an ever-evolving system of dispositions subject to the influences of the social world in which individuals are socialised and their practices materialised (Bourdieu and Wacquant 1992). The Participatory Web shapes the practices of scholars who use it as part of their professional activity because it provides them with alternative forms of communication and dissemination of their work, and also meets their goals in trying to network and open their scholarly activity to wider audiences. Notwithstanding, this change in practice is as much related to the new technological solutions made available through the Participatory Web as it is to the ideas and practices that take place within the networks that digital scholars join or form. The networks of the research participants act as supporting structures that not only influence their outlook on practice but also instigate and vindicate their beliefs and convictions regarding how they should conduct their scholarly practice with the support of new technologies. This not only strengthens the research participants' habitus regarding their scholarly activity, as they enjoy the support of their social networks, but it also reinforces their embodied cultural capital as the practices in which they engage are supported by their social capital.

In short, the research participants' overall perception of scholarship for the $21 \mathrm{st}$ century is deeply rooted in the socio-cultural norms of the spaces in which they participate online, establish links and socialise as part of their professional practice. Their perceptions not only apply to their online activity but rather to their scholarly activity as a whole. Hence, in studying research participants' perceptions of their own digital scholarship practices, we can identify the following dispositions that illustrate their habitus: 
- They are highly reflective of the purpose of their profession: the research participants' use of the Participatory Web in their scholarly practice is related to the values they share about their scholarly activity and which purpose they aim to serve. In doing so, they question the established practices as they use the Participatory Web as both a tool and conduit for innovation of knowledge work.

- They are committed to openness: the research participants' see themselves as knowledge workers working for the public good. Their willingness to be transparent and open about their practice aims to benefit not only their peer communities but also those that their practice aims to inform, improve and make a difference. E.g. their profession, area of studies/practice they work on.

- They value their extended online networks and online communities: The research participants put a great emphasis on their peer networks not only as a form of fostering new collaboration but also of co-creating new opportunities for learning and construction of knowledge. Online peer networks also provide validation of their ideas and approaches to practice, hence strengthening their identity as digital scholars.

- They want to make a difference: The research participants want to make a difference with their scholarly work. The use of the Participatory Web enables them to conduct, discuss and present their scholarly activity in new ways that are more congruent with current practices, as knowledge becomes much more accessible online and more available to be (re-)used and discussed.

In short, digital scholarship is a mind-set. Engagement in digital scholarship practices, as outlined by Weller (2011), results in the development of dispositions that reflect the world of practice of research participants. Their engagement in digital, open and networked practices is unconventionally different from the approaches and practices conducted by scholars who do not embrace the three main characteristics of digital scholarship, as highlighted in Figure 1.

In this article, I have aimed to demonstrate that the introduction of digital technologies has encouraged new forms of scholarship, and it is also stimulating the development of new epistemologies of practice - ideas and knowledge that inform practice - that are typified by the beliefs and values research participants share with regard to their professional activity. Weller's categorisation of digital scholarship provided a useful framework to illustrate the principles and beliefs that underpin the habitus of digital scholars. This research has aimed to inform to reader of the traits and beliefs that characterise emergent, contemporary form of digital scholarship practices that go beyond the access and upload of academic knowledge. Current forms of digital scholarship practices also involve active engagement in the debates of openness and transparency of knowledge creation, which often occur within the online social networks to which scholars belong. Digital scholarship practices will continue to evolve as the Participatory Web will continue to present its users with the latest innovations.

Nonetheless, it is also important to understand the interplay between the habitus of digital scholars and the different fields in which their practices occur. This article looked at the habitus of digital scholars within the context of their online networks and the ideas herein advocated. Future research will consider the habitus of digital scholars within the context of research participants' institutions as they may displays 


\section{Costa}

a different set of rules and conventions that might contradict or explore online practices in a totally different way.

\section{References}

Anderson, T. \& Dron, J. (2011) 'Three generations of distance education pedagogy', The International Review of Research in Open and Distance Learning, vol. 12, no. 3, pp. 80-97.

Anderson, T. \& Dron, J. (2012) 'Learning technology through three generations of technology enhanced distance education Pedagogy', European Journal of Open, Distance and E-Learning, [online] Available at: http://www.eric.ed.gov/ERICWebPortal/detail?accno= EJ992485

Attwell, G. (2006) 'E-Learning und die sociale Gestaltung der Technik', in Die Wissensgesellschaft, Mythos, Ideologie oder Realitat, eds U. Bittingmayer \& U. Bauer, VS Verlag fur Soczialwissenschaften, Wiesbaden, pp. 1-25.

Bennett, W. L., Wells, C. \& Freelon, D. (2011) 'Communicating civic engagement: contrasting models of citizenship in the Youth Web Sphere', Journal of Communication, vol. 61, pp. $835-856$.

Bonk, C. J. (2009) The World is Open: How Web Technology is Revolutionizing Education, John Wiley, San Francisco, California.

Bourdieu, P. (1985) 'The social space and the genesis of groups', Theory and Society, vol. 14, pp. 723-744.

Bourdieu, P. (1986) 'The forms of capital' in Handbook of Theory and Research for the Sociology of Education, ed J. Richardson, New York, Greenwood, pp. 241-258.

Bourdieu, P. (1990a) Homo Academicus, Stanford University Press, Standford, California.

Bourdieu, P. (1990b) The Logic of Practice, Stanford University Press, Standford, California.

Bourdieu, P. (2000) Pascalian Meditations, Stanford University Press, Standford, California.

Bourdieu, P. \& Wacquant, L. J. D. (1992) An Invitation to Reflexive Sociology, University of Chicago Press, Chicago.

Boyer, E. L. (1990) Scholarship Reconsidered: Priorities of the Professoriate, Carnegie Foundation for the Advancement of Teaching, New York.

Brown, J. S. (2002) 'Growing up digital: how the web changes work, education, and the ways people learn', USDLA Journal, vol. 16, pp. 11-20.

Bruner, J. (1991) 'The narrative construction of reality', Critical Inquiry vol. 18, no. 1, pp. 1-21.

Bruner, J. (1992) Acts of Meaning, New edn, Harvard University Press, Harvard, USA.

Cammaerts, B. (2008) 'Critiques on the participatory potentials of Web 2.0', Communication, Culture \& Critique, vol. 1, pp. 358-377.

Choo, C.W., Detlor, B. \& Turnbull, D. (2000) Web work: information and seeking knowledge work on the World Wide Web. Spring.

Clandinin, D. J. (2006) 'Narrative inquiry: a methodology for studying lived experience', Research Studies in Music Education, vol. 27, pp. 44-54.

Clandinin, D. J. \& Connelly, F. M. (2004) Narrative Inquiry: Experience and Story in Qualitative Research, San Francisco, Jossey-Bass.

Conole, G. (2012) Chapter: New Approaches to Openness - Beyond Open Educational Resources, Cloudworks.

Deibert, R. (2009) 'The geopolitics of internet control: censorship, sovereignty, and cyberspace', in Routledge Handbook of Internet Politics, ed A. Chadwick, Taylor \& Francis, New York, pp. 323-336.

Drucker, P. (1998) 'The next information revolution', FORBES ASAP, pp. 47-58.

Eijkman, H. (2010) 'Dancing with postmodernity: Web $2.0+$ as a new epistemic learning space', in Web 2.0-Based E-Learning: Applying Social Informatics for Tertiary Teaching, eds M. J. W. Lee \& C. McLoughlin, Idea Group Inc (IGI), Hershey, PA, USA, pp. 343-364.

Elam, A. B. (2008) Gender and Entrepreneurship: A Multilevel Theory and Analysis, Edward Elgar, Herbey, PA, USA.

Grenfell, M. (2008) Pierre Bourdieu: Key Concepts, Acumen, Durham, UK.

Hessels, L. K. \& van Lente, H. (2008) 'Re-thinking new knowledge production: a literature review and a research agenda', Research Policy, vol. 37, pp. 740-760.

Hjorth, L. \& Arnold, M. (2011) 'The personal and the political: social networking in Manila', International Journal of Learning and Media, vol. 3, pp. 29-39. 
Jarrett, K. (2008) Interactivity is Evil! A critical investigation of Web 2.0. First Monday 13.

Jones, J. (2011) 'Social media and social movements', International Socialism: A Quarterly Journal of Social Theory, Spring.

Krishnamurthy, B. \& Cormode, G. (2008) 'Key differences between Web 1.0 and Web 2.0', First Monday, vol. 13, pp. 1-19.

Lawler, S. (2002) 'Narrative in social research', in Qualitative Research in Action, ed T. May, Sage, London, pp. 242-258.

Lenhart, A. et al. (2010) 'Social media \& mobile internet use among teens and young adults', Pew Internet American Life Project, vol. 5, pp. 1-37.

Levy, M. (2009) 'WEB 2.0 implications on knowledge management', Journal of Knowledge Management, vol. 13, pp. 120-134.

Levy, P. (1997) Collective Intelligence: Mankind's Emerging World in Cyberspace (Helix Books), Perseus Books Group, USA.

Liang, B. \& Lu, H. (2010) 'Internet development, censorship, and cyber crimes in China', Journal of Contemporary Criminal Justice, vol. 26, no. 1, pp. 103-120.

McLuhan, M. (1964) Understanding Media: The Extensions of Man, Routledge, MIT press edition. USA.

Naughton, J. (2012) From Gutenberg to Zuckerberg: What You Really Need to Know About the Internet, London, Quercus.

Noble, G. \& Lupton, D. (1998) 'Consuming work: computers, subjectivity and appropriation in the university workplace', The Sociological Review, vol. 46, pp. 803-827.

Patton, M. Q. (1990) Qualitative Evaluation and Research Methods, 2nd edn, Sage, London.

Patton, M. Q. (2002) Qualitative Research and Evaluation Methods, Sage, London.

Powell, W. W. \& Snellman, K. (2004) 'The knowledge economy', Annual Review of Sociology, vol. 30, pp. 199-220.

Ray, T. (2011) 'The 'story' of digital excess in revolutions of the Arab Spring', Journal of Media Practice, vol. 12, pp. 189-196.

Reay, D. (2004) 'It's all becoming a habitus': beyond the habitual use of habitus in educational research', British Journal of Sociology of Education, vol. 25, pp. 431-444.

Rheingold, H. (2007) 'Using participatory media and public voice to encourage civic engagement', Rheingold: The John D. and Catherine T. MacArthur Foundation Series on Digital Media and Learning, London, pp. 97-118.

Riessman, C. K. (1993) Narrative Analysis, Sage, London.

Shirky, C. (2011) 'The political power of social media', Foreign Affairs, vol. 90, pp. 1-9.

Surowiecki, J. (2005) The Wisdom of Crowds: Why the Many Are Smarter Than the Few, New edn, ed Abacus, New York, USA.

Topp, L., Barker, B. \& Degenhardt, L. (2004) 'The external validity of results derived from ecstasy users recruited using purposive sampling strategies', Drug and Alcohol Dependence, vol. 73 , pp. $33-40$.

Townsend, A. M., DeMarie, S. M. \& Hendrickson, A. R. (1998) 'Virtual teams: technology and the workplace of the future', The Academy of Management Executive (1993-2005), vol. 12, pp. 17-29.

Veletsianos, G. \& Kimmons, R. (2012) 'Networked participatory scholarship: emergent techno-cultural pressures toward open and digital scholarship in online networks', Computers \& Education, vol. 58, pp. 766-774.

Weller, M. (2011) The Digital Scholar: How Technology is Changing Academic Practice, Bloomsbury, London.

Zimmer, M. (2008) 'Preface: critical perspectives on Web 2.0', First Monday, vol. 13. 